\title{
LA DOBLE FACETA DE LA LIBERTAD DE TRABAJO Y SU PROTECCIÓN EN LA CONSTITUCIÓN CHILENA
}

\author{
JUAN PABLO HERRERA VERGARA ${ }^{1}$
}

\section{Resumen}

Tras el advenimiento del derecho del trabajo, en el siglo XX el nuevo constitucionalismo permite una eficacia plena de los derechos fundamentales en la empresa. En dicho contexto, mediante una misma disposición como es el artículo 19 número 16, se puede graficar el cruce en nuestra Constitución Política de los derechos fundamentales de trabajadores y empleadores.

\section{Palabras claves}

Constitución Política, libertad de trabajo, protección al trabajo.

\begin{abstract}
After the emergence of labor law, the new constitutionalism of the twentieth century allows a full effectiveness of fundamental rights in the company. In this context, under the same provision enshrined in Article 19 number 16, it is possible to depict the crossing of fundamental rights of workers and employers in our Constitution.
\end{abstract}

\section{Keywords}

Political Constitution, freedom of work, protection of work.

$1 \quad$ Magíster en derecho del trabajo y la seguridad social por la Universidad de Chile. Santiago, Chile. Correo electrónico: jpherrera@quijadaabogados.cl. 


\section{Perspectiva y objetivos del trabajo.}

Antes de abordar la problemática de esta investigación centrada en el encuentro de los derechos constitucionales de las partes que interactúan en la relación laboral, resulta importante abocarse a conocer el contexto en el cual surge el derecho laboral. Disciplina que sienta la regulación para que, tras el surgimiento del estado social de derecho y la constitucionalización del derecho del trabajo, arribe la eficacia horizontal de los derechos fundamentales.

Nuevo constitucionalismo que hace eclosión en el siglo XX, en virtud de lo cual, por un lado, se encuentran los derechos fundamentales de los trabajadores que "se oponen a los poderes empresariales, poder que tiene su fundamento en los derechos fundamentales del empleador" y, en virtud de aquello, se deben determinar "los límites que esos derechos fundamentales -los de los trabajadores- deben soportar por ejercerse dentro del marco normativo de un contrato de trabajo".

Cruce graficado en una disposición constitucional, específicamente el artículo $19 \mathrm{~N}^{\mathrm{o}} 16$ de la Constitución Política, ${ }^{3}$ respecto de la cual no existe consenso, en el sentido de que parte de la doctrina considera que debe entenderse exclusivamente con su cariz literal de protección a la libertad de trabajo, mientras que para otros autores de este enunciado se deriva, igualmente, la protección del trabajo mismo. Si bien sobre el análisis de estas aristas se centra el objetivo de este trabajo, el mismo parte de la premisa de que en dicha disposición conviven la protección a derechos, de naturaleza contrapuesta, detentados por ambas partes del contexto laboral.

Con todo, más allá de la controversia sobre un precepto en particular, resulta insoslayable que la Constitución Política consagra derechos fundamentales para ambas partes del contexto laboral.

Por un lado, los derechos fundamentales del trabajador desplegados en la empresa donde ejerce su trabajo asalariado, como en cualquier otra instancia de la sociedad civil donde interactúe, deben ser respetados, el trabajo no es una excepción. Esto es un argumento por lo que se ha producido "la

2 UGARTE, José Luis: Derechos Fundamentales en el Contrato de Trabajo. Editorial Thomson Reuters, Santiago, 2013. p. 38.

3 Que en sus primeros dos incisos señala: "La libertad de trabajo y su protección. Toda persona tiene derecho a la libre contratación y a la libre elección del trabajo con una justa retribución". 
proyección de los derechos ciudadanos del trabajador al interior del contrato de trabajo, específicamente como límites al poder del empleador". ${ }^{4}$

Sin perjuicio de que los derechos fundamentales del trabajador poseen plena eficacia en el marco laboral, éstos deben compatibilizarse y, por lo mismo, "se ven expuestos a restricciones por la existencia de deberes laborales y derechos del empresario previstos en la regulación laboral ordinaria, ya sea de origen legal o de origen contractual, en lo que la doctrina ha venido denominando 'modulización' de dichos derechos". 5

De la naturaleza del problema planteado, consistente en dilucidar si efectivamente estamos frente a una disposición bisagra del encuentro de derechos antagónicos, se deriva la relevancia del presente estudio. En el entendido de que más allá del hecho de considerar simplemente una doble mirada a los derechos fundamentales en el contexto de las relaciones laborales, sino que, por el contrario, estamos en presencia, como lo denomina José Luis Ugarte, del problema de la 'capacidad conformadora' de los derechos fundamentales en la relación laboral. Vale decir, "las limitaciones de que son objetos los poderes empresariales en su calidad de manifestación de los derechos fundamentales del empresario -libertad de empresa y/o derecho de propiedad - a resultas de la oposición de iguales derechos por parte del trabajador, corresponde a un problema de equilibrio entre derechos de igual relevancia jurídico-formal o jerarquía". ${ }^{6}$

Frente a este 'conflicto normativo' Ugarte postula como solución el método de la ponderación entre derechos y el principio de proporcionalidad, basado en el método de Robert Alexy. El cual ha sido ampliamente explicado por la doctrina, sin perjuicio de que su análisis acabado no es el objeto del presente trabajo, ${ }^{8}$ someramente cabe señalar que el 'método de la ponderación' se grafica en la siguiente fórmula: "Cuando mayor sea el grado de no satisfacción o restricción de uno de los principios, tanto mayor deberá

4 GAMONAL, Sergio: Fundamentos de Derecho Laboral. Tercera edición. Editorial Thomson Reuters, Santiago, 2012. p. 79.

$5 \quad$ UGARTE, Derechos Fundamentales, ob. cit., p. 38.

$6 \quad$ Ibidem, p. 39.

7 Ibidem, p. 40.

$8 \quad$ Considerando que esta investigación pretende graficar la existencia del encuentro de estos derechos y la eventual colisión que vive latente en un precepto constitucional, analizando algunas aristas del contexto jurídico social que posee dicha regulación. No siendo el objetivo de este trabajo estudiar las posibles soluciones a diferentes casos específicos de colisión, lo cual podría ser materia de una investigación en el marco del procedimiento de tutela laboral por vulneración de derechos fundamentales. 
ser el grado de importancia de la satisfacción del otro". ${ }^{9}$ Explicando de tal modo Alexy con una fórmula lógica a efectos de 'pesar' los principios en juego. En el plano práctico dicha fórmula significa que el ejercicio de un derecho puede verse afectado por el desarrollo de otro derecho, frente a lo cual, para saber el grado de 'concesión' recíproca que se realizan estos dos derechos eventuales en colisión, deben 'pesarse', es decir, se debe determinar la relevancia y valor jurídico que poseen.

Desde una perspectiva metodológica, cabe referirse a las herramientas que nos guiarán sobre la interpretación jurídica de una disposición complejamente redactada. En tal sentido, Riccardo Guastini, señala que interpretar -que implica realizar una atribución de significado- puede tener una doble faceta, entendiendo que es susceptible de estudiarse en un sentido restringido, como "la atribución de significado a una formulación normativa en presencia de dudas o controversias en torno a su campo de aplicación" o, por el contrario, la interpretación "se emplea para referirse a cualquier atribución de significado a una formulación normativa, independiente de dudas o controversias". ${ }^{10}$

En base al primer postulado interpretativo, esta actividad sólo sería necesaria cuando se está en presencia de casos oscuros o dudosos, mientras que, siguiendo una perspectiva amplia, siempre que se atribuye significado a un texto se está interpretando, una cuestión diferente es si un caso determinado, dependiendo de su complejidad, se requerirá una mayor argumentación.

Considerando la naturaleza de la norma en la que se centra el presente análisis, en virtud de lo cual pareciera justificarse el ejercicio de interpretación frente a una norma intrincada como es aquella, no obstante lo cual, se seguirá la segunda concepción de interpretación. Aquello teniendo en cuenta que el operador jurídico, específicamente el juez, cada vez que realiza el proceso de subsunción de una disposición legal está realizando un ejercicio de interpretación, independiente si el contenido de la disposición es claro o intrincado.

En dicha línea, el artículo $19 \mathrm{~N}^{\mathrm{o}} 16$ de la Constitución Política es la disposición jurídica a estudiar, de cuyo vaivén interpretativo nace la norma

9 ALEXY, Robert: "La fórmula del peso", en Carbonell, Miguel (edit.): $E l$ principio de proporcionalidad en la interpretación jurídica. Editorial Librotecnia, Santiago, 2010. p. 17.

10 GUASTINI, Riccardo: Estudios sobre interpretación jurídica., Editorial del Instituto de investigaciones jurídicas de la UNAM, México, D.F., 1990. pp. 3-4. 
que regulará el caso concreto donde exista una controversia. Lo anterior, comprendiendo que disposición es todo enunciado perteneciente a una fuente del derecho, mientras que norma es el sentido de la disposición, su significado, es una variable dependiente de la interpretación. Así, la disposición constituye el objeto de la actividad interpretativa y la norma su resultado. ${ }^{11}$

Mientras que, a efectos de entender el contexto regulatorio de la disposición analizada, será relevante recurrir al marco de los planteamientos sobre argumentación jurídica que realiza Francisco Ezquiaga. Específicamente en relación con las categorías interpretativas consistentes en los argumentos sistemáticos y teleológico. Refiriéndose al argumento sistemático en específico Ezquiaga señala: "en las culturas jurídicas modernas el conjunto de preceptos que forman un ordenamiento jurídico concreto es concebido, no como una mera adición, sino como un sistema", ${ }^{12}$ por su parte, respecto al argumento teleológico apunta dicho autor que "consiste en justificar la atribución de un significado apelando a la finalidad del precepto, por entender que la norma es un medio para un fin". ${ }^{13}$

Todo lo cual se inserta en los objetivos del presente análisis, teniendo en cuenta que, para interpretar, en el sentido de que se le 'atribuye significado' a la disposición que se estudia, la misma debe comprenderse armónicamente con las demás disposiciones constitucionales -e internacionales, como se verá- que correspondieren.

\section{Una vuelta de tuerca.}

El problema respecto de la eventual colisión de derechos fundamentales en la relación laboral posee su origen en un marco conceptual mayor, tal como es el cambio de paradigma del "Estado liberal al Estado social de Derecho -fundamentalmente con la Constitución de Weimar de 1919 - dando así respuesta a la dicotomía y tensión existente entre libertades individuales y colectivas, constituyéndose, a su vez, en el texto constitucional inspirador de las cartas constitucionales europeas de entre guerras. Su importancia, a

\footnotetext{
$11 \quad$ Ibidem, pp. 10-13.

12 EZQUIAGA, Francisco: "Argumentos interpretativos y postulado

del legislador racional". 1994. Disponible en: http://www2.scjn.gob.mx/red2/

investigacionesjurisprudenciales/seminarios/2o- seminario-jurisprudencia/modulo-

vii/04francisco-ezquiaga-argumentos-interpretativos.pdf. Fecha de consulta: 19 de marzo de 2018. p. 88.

13 Ibidem, p. 95.
} 
nuestros efectos, radica en que, a partir de ella, la constitución pasa a ser ley fundamental tanto del derecho público como el privado". ${ }^{14}$

Tal como señala Christian Melis, de la mano de profundas trasformaciones sociales, a comienzo del siglo XX, el fenómeno constitucional se hace eco de comprender que las grandes libertades de las que se empoderó la sociedad civil desde finales del siglo XVIII, se manifestaban fisuradas en el plano práctico.

Parafraseando a Henry James, en este capítulo se analizará, brevemente, el cambio de paradigma que significó el surgimiento del Estado social de derecho, y los matices de lo que se ha denominado la 'constitucionalización' del derecho del trabajo, no obstante, antes que este 'empoderamiento constitucional', por llamarlo de algún modo, surge como respuesta a la 'urgencia social' -consecuencia de la falta de una regulación especial que equilibrara las relaciones laborales- el derecho del trabajo.

\section{La respuesta normativa a una situación social insostenible.}

Durante el desarrollo del siglo XIX, rápidamente se vislumbró que las libertades políticas surgidas a partir de la revolución francesa necesitaban 'arquetipos' donde desarrollarse plenamente, lo que podía traducirse en un simple imaginario de plenitud de derechos, como es el caso del trabajo estandarizado en la fábrica.

Lo cual resultaba lógico teniendo en cuenta la profunda transformación que vivieron los actores que protagonizaban las relaciones productivas. Considerando que en el antiguo régimen el desempeño de una actividad laboral implicaba que una persona estaba ligada estatutariamente a su oficio, limitando su actuar productivo a la actividad profesional ejercida, mientras que, tras la revolución francesa, repentinamente concluyeron estas cortapisas a la libertad de trabajo, primero, con el Edicto de Turgot, suprimiendo los gremios en $1776 \mathrm{y}$, posteriormente, con la Ley Chapelier, terminando con las corporaciones en $1791 .^{15}$

En palabras de Ernest Junger esta situación explica por qué "la libertad de trabajo es el nuevo calco del patrón burgués de la libertad, un nuevo cal-

14 MELIS, Christian: Los derechos fundamentales de los trabajadores como limites a los poderes empresariales. Legal Publishing, Santiago, 2009. p. 7.

15 IRURETA, Pedro: Constitución y orden público laboral. Un análisis del art. 19 $N^{\circ} 16$ de la Constitución chilena. Segunda edición. Ediciones Universidad Alberto Hurtado, Santiago, 2012. p. 10. 
co en el que ahora se interpreta abiertamente el destino como una relación contractual a plazo y se interpreta el triunfo supremo de la vida como una modificación de ese contrato...el trabajador es la copia de la imagen ideal de la humanidad cuya mera utopía encierra ya en sí la negación del Estado y de sus cimientos". ${ }^{16}$

No obstante, resulta evidente la fisura de este ideario, por cuanto, tal como Anton Menger esbozaba hace más de un siglo -citado por Giovanni Cazzetta- "la libertad ilimitada entre seres desiguales no significa más que la libertad del más fuerte para oprimir al más débil, o sea, la negación de la misma libertad y una violación del derecho". ${ }^{17}$

La fábrica, precisamente, era el centro neurálgico donde se manifestaba este desequilibrio, adquiriendo un protagonismo inusitado en el engranaje social. "Así es con toda seguridad-como complementa Dominique Meda-, puesto que hemos llegado a organizar todas las relaciones sociales en torno al trabajo y desde hace dos siglos nuestras sociedades parecen haberse fijado por objetivo fundamental la consecución de la abundancia. De ahí el que no consigamos imaginar otros tipos de actividades colectivas, otras maneras de expresarse ni otro fundamento del vínculo social que el trabajo". ${ }^{18}$

Rol abrumador de una institución 'prototipo' de la sociedad industrial sobre la integridad psíquica y física de las personas, como es la fábrica, que ampliamente fue desarrollado por Michel Foucault en el libro ' $\mathrm{La}$ verdad y las formas jurídicas', particularmente en el capítulo $\mathrm{V}$ denominado "La inclusión forzada: el secuestro institucional del cuerpo y del tiempo personal". ${ }^{19}$

Foucault describe el reglamento interno de una institución francesa de mediados del siglo XIX, mediante la cual plantea, como una adivinanza al lector, a efectos de si logra dilucidar si la descripción que realiza se refiere al reglamento de una prisión, un hospital psiquiátrico, una escuela, un cuartel, o una fábrica. Describiendo detalladamente una jornada diaria distribuida a los residentes de acuerdo con los requerimientos de dicha institución, el estricto reglamento de conducta que se impone, la obligación diaria

16 JUNGER, Ernest: El trabajador. Dominio y figura. Tercera edición. Editorial Ensayo Tusquets, Barcelona, 2003. p. 31.

17 CAZZETA, Giovanni: Estado, Juristas y Trabajo. Itinerarios del Derecho del Trabajo en el siglo XX. Editorial Marcial Pons, Madrid, 2010. p. 75.

18 MEDA, Dominique: "El valor del Trabajo visto en perspectiva". En: Revista Internacional del Trabajo, vol. 115, $\mathrm{N}^{\circ} 6,1996$. p. 694.

19 FOUCAULT, Michel: La verdad y las formas jurídicas. Editorial Gedisa, Barcelona, 2010. p. 121. 
de orar, la prohibición de salir del recinto y de compartir entre hombres y mujeres, entre variadas otras reglas.

Claramente estamos en presencia de una fábrica, sin embargo, más allá de la institución de la que se tratare, lo relevante de su descripción es considerar que tanto en aquel contexto temporal como hoy -con claros matices, por cierto, si lo extrapolamos al presente-, la finalidad de toda institución no es excluir, "sino, por el contrario, fijar a los individuos. La fábrica no excluye a los individuos, los liga un aparato de producción". ${ }^{20} \mathrm{Al}$ igual que toda gran institución, porque podría haberse tratado de una escuela o una cárcel, a entender de Foucault la fábrica posee la lógica de la inclusión por exclusión, ${ }^{21}$ vale decir, posee un potencial para afectar variados derechos fundamentales de los trabajadores. No sólo el poder público puede afectar estos derechos.

Las personas, ya sea en el trabajo como en el de cualquier otro ámbito donde se desempeñaban, debían encauzar el goce de sus derechos a los requerimientos institucionales impuestos. ${ }^{22}$ En virtud de lo cual "el trabajador no se revelará - como complementa Junger a comienzos del siglo $\mathrm{XX}$ - como el verdadero enemigo mortal de la sociedad mientras no rechace pensar, sentir y ser dentro de las formas propias de ella". ${ }^{23}$ Ausencia de regulación propia para las relaciones entre patrón y obrero que otorgaron un marco ideal para abusos. Tal como ocurre muchas veces con el derecho, las formas jurídicas carecían de sintonía con el escenario real donde transcurrían -en este caso- las relaciones productivas.

Es conocido el fenómeno de la cuestión social, respecto del cual -refiriéndonos sin ahondar en el mismo- Sergio Grez rescata la definición, concerniente al periodo que abarca desde 1880 a 1920, que realiza James O. Morris, entendiéndola como "la totalidad de las consecuencias sociales,

\footnotetext{
$20 \quad$ Ibidem, p. 135.

$21 \quad$ Ibidem, p. 135.

22 ZIZEK, Slavoj: Repetir Lenin. Editorial Akal, Madrid, 2004. p. 15: Aunque no se presenta con la crudeza del siglo XIX, en la sociedad actual, según Slavoj Zizek, la situación no es radicalmente diferente, por el contrario, "nuestra experiencia cotidiana es más mistificadora que nunca: la propia modernización genera nuevos oscurantismos, la reducción de la libertad se nos presenta como la llegada de nuevas libertades. La percepción de que vivimos en una sociedad de elecciones libres, en la que tenemos que elegir hasta nuestros rasgos más naturales (la identidad étnica o sexual), es la forma de aparición de su extracto contrario, de la ausencia de verdaderas opciones". Mientras que a nivel laboral la situación contemporánea, donde la facturación en masa se realiza lejos de la mirada del 'primer mundo', como complementa Zizek, en el imaginario público el trabajo se ha equiparado con "el delito, la idea de que la labor, el trabajo penoso, es desde el principio una actividad criminal indecente que no puede ser expuesta a la mirada pública". p. 104. 23

JUNGER, ob. cit., p.33.
} 
laborales e ideológicas de la industrialización y de la urbanización nacientes: una nueva fuerza de trabajo dependiente del sistema de salarios, la aparición de problemas cada vez más complejos pertinentes a vivienda obrera, atención médica y salubridad; la constitución de organizaciones destinadas a defender los intereses de la nueva "clase trabajadora'....". ${ }^{24}$

La ausencia de una respuesta jurídica no se condecía con la urgencia que poseían los fenómenos y las reivindicaciones sociales crecientes. De tal modo, frente a este páramo regulatorio surge precisamente el derecho laboral, el cual se convierte, como señala Giovanni Cazzetta, citado por Gamonal, en un "peculiar instrumental técnico, nacido para hacer menos despiadado el trabajo en la sociedad industrial". ${ }^{25}$

Análisis que se condice con la apreciación realizada por Alain Supiot en el sentido de que "la noción del derecho del trabajo es reciente y evolutiva. $\mathrm{Su}$ desarrollo está relacionado con el nacimiento y el desarrollo del trabajo remunerado en los países denominados capitalistas, cuya economía reposa en la libertad de comercio y de la industria". ${ }^{26}$

Por lo que no es casualidad de que en Francia y en Alemania surgieran las primeras disposiciones legales tendientes a regular el trabajo dependiente. Como enseñaba Francisco Walker Linares, en Francia, cuna precisamente de las libertades políticas que, no obstante aquello, trajeron aparejadas claras desigualdades prácticas, por lo que "sólo poco después de la Revolución de 1848, Francia intervino legalmente por primera vez en el trabajo, reduciendo a doce horas las jornada de trabajo industrial", mientras que "la Alemania imperial dirigida por Bismarck abrió el ciclo de la leyes obreras contemporáneas con una completa legislación de seguros sociales, dictada para detener los avances del socialismo, y que fue más tarde imitada por Austria-Hungría". ${ }^{27}$

Lectura que parece muy apropiada, con todo, aunque su objetivo primigenio fuese frenar el evidente descontento social imperante más que poseer fines altruistas para frenar el abuso contra los trabajadores, lo concreto es que "a lo largo de todo el siglo XX, el derecho del trabajo fue la disciplina

24 GREZ, Sergio: De la regeneración del pueblo a la huelga general. Génesis y evolución histórica del movimiento popular en Chile (1810-1890). Segunda edición. Editorial Ril, Santiago, 2007. p. 183.

25 GAMONAL, ob. cit., p.8.

26 SUPIOT, Alain: Derecho del Trabajo., Editorial Eliasta, Buenos Aires, 2008. p. 9.

27 WALKER, Francisco: Nociones Elementales de Derecho del Trabajo. Editorial Nascimiento, Santiago, 1941. p. 158. 
que, en mayor medida que ninguna otra, tuvo a su cargo la tarea de ofrecer respuestas a las trasformaciones sociales", tal como agrega Gioanni Cazzetta. $^{28}$

Corolario de lo cual, el título de este acápite, reflejado de manera general y resumida, obedece a entender que el derecho del trabajo es precisamente la respuesta normativa a una situación social insostenible.

\section{El empoderamiento de los derechos fundamentales.}

Tal como se ha venido analizando, "la falta de regulación del trabajo que supuso la concepción del Estado liberal comenzó a resquebrajarse...y el esquema constitucional comenzó a dejar al descubierto un conflicto estructural de intereses que exigía una regulación por parte de los textos normativos" 29 .

La cuestión social provocada por la revolución industrial, los fenómenos revolucionarios del siglo XIX, como el de París de 1848, son antecedentes que ponen de manifiesto, tal como sostiene De Otto, citado por Pedro Irureta, "que los mecanismos de la sociedad civil no bastan por sí solos para garantizar un mínimo de armonía social y bienestar económico", lo cual se habría plasmado en incorporar en los Códigos políticos, como sucedió en las constituciones de Querétaro y Weimar, "un conjunto de derechos -de segunda generación- que plasmaban el compromiso del Estado a favor de una mayor igualdad material". De tal forma se reconoce que el poder se difumina en la sociedad, el cual no es monopolio exclusivo del Estado. ${ }^{30}$

Estamos en presencia de un giro en la visión liberal de concebir a los derechos fundamentales como un medio de defensa frente a la autoridad pública exclusivamente; este cambio de paradigma se debe a que se vislumbran "entes sociales privados que ejercen cuotas significativas de poder -entendido éste como la capacidad de dirigir realmente la conducta de otros- y que influyen e inciden en el desarrollo de las libertades del individuo". ${ }^{31}$ Un ejemplo de estos centros de poder privado que pueden ejercer coacción sobre las libertades y derechos de los individuos es la empresa, como se analizó en el acápite precedente.

\begin{tabular}{ll}
\hline 28 & CAZZETA, ob. cit., p. 87. \\
29 & IRURETA, ob. cit., p. 13. \\
30 & Ibidem, p. 13. \\
31 & MELIS, ob. cit., p. 12.
\end{tabular}


Consecuencia de la cual, mientras que en el contexto de la concepción liberal de los derechos fundamentales aquellos solo poseen una lógica de interacción entre el individuo y la autoridad estatal, de forma paulatina, y de la mano de reivindicaciones sociales, esta interacción decantó en el ámbito cotidiano. Primero, es el derecho del trabajo, y su naciente regulación normativa que se hace eco de un fenómeno social que se hacía insostenible, por su parte, ya adentrados en el siglo XX irrumpe, tras la constitucionalización del derecho del trabajo, la eficacia horizontal de los derechos fundamentales, conforme a la cual estos derechos tienen plena eficacia entre particulares, como puede ocurrir en la empresa.

Lo anterior encuentra su sustento doctrinario en la teoría alemana del Drittwirkung der Grundrechte, la que ha sido objeto de diversas interpretaciones, sin perjuicio de lo cual, "en su versión original correspondía a la eficacia inmediata, estaba, como ya se ha señalado, influenciada por la teoría de los valores en términos tales que el propio impulsor de esta teoría, Nipperdey, quien entendía que los derechos fundamentales constituían principios objetivos y vinculantes que influían en las relaciones 'inter privatos', de ellos fluyen directamente también derechos subjetivos del individuo. Se produce entonces un efecto absoluto de los derechos fundamentales, que ha de afectar directamente al ciudadano alterando o modificando las normas de derecho privado existentes". ${ }^{32}$

La función de los derechos fundamentales pasa a ser la de limitadoras del poder, ya sea este público o privado. Las normas constitucionales de derechos fundamentales son de aplicación directa y no meros elementos de interpretación para las relaciones entre privados. De tal forma, la norma que decide el conflicto es constitucional 'directamente' y no legal como propugna la teoría contraria, de la eficacia mediata. ${ }^{33}$

Con todo, y pese a que la anterior es la postura de la doctrina nacional mayoritaria, esta perspectiva posee matices.

A tal respecto, Eduardo Aldunate sostiene que "la posibilidad de derivar directamente, a partir de los derechos fundamentales, deberes de actuación o abstención para otros particulares, lo que implica una limitación a sus libertades, o sea, un efecto horizontal inmediato, es de carácter discutible". ${ }^{34}$

$32 \quad$ Ibidem, p. 24.

33 Ibidem, p. 25.

34 ALDUNATE, Eduardo: Derechos Fundamentales. Editorial Thomson Reuters, Santiago, 2008. p. 221. 
La premisa de una eficacia horizontal inmediata, en relación con la aplicación directa entre los particulares de derechos fundamentales -explica Aldunate- puede conducir a resultados tan absurdos como el abandono de la ley como reguladora de la libertad de uno en relación con la libertad de otro y dejar entregada al juez esa delimitación, sin parámetros normativos, perdiendo con ello la característica de generalidad de la ley. A modo de ejemplo, señala Aldunate, dada una misma situación específica, para un individuo pudieran verse involucrados ciertos derechos fundamentales, mientras que, para un segundo sujeto, verse en juego, en la misma situación, otros derechos disímiles. ${ }^{35}$

Aldunate agrega que, asimismo, se puede graficar la crítica a la eficacia directa de los derechos fundamentales, en nuestro país, a propósito de la proscripción de la arbitrariedad. "El núcleo más auténtico de la libertad individual consiste precisamente, en la posibilidad de un actuar arbitrario, el que no sólo se encuentra al margen de la regulación jurídica, sino que escapa a toda exigencia de fundamentación". ${ }^{36}$

Para este autor, la posibilidad de un actuar arbitrario, es la manifestación más profunda de la subjetividad. Escenario que implica interiorizarnos en las emociones y preferencias personales, las que ni siquiera logran, o necesitan, una validación social. Por ejemplo, invitar a alguien a tomar un café por el simple hecho que nos provoca simpatía, mientras que, por el contrario, no tenemos que justificar la negativa de invitar a quien nos es antipático. ${ }^{37}$

Aldunate reconoce que parecieran existir prohibiciones de discriminación arbitraria, dirigidas al actuar entre particulares, y no sólo respecto del Estado, como es el caso del artículo $19 \mathrm{~N}^{\circ} 16$, inciso 3, de la Constitución Política, ${ }^{38}$ sin embargo, de no entenderse esta norma con un carácter limitativo entre particulares, se caería en el absurdo de considerar que la única libertad que le queda a las personas, en este ámbito, "sería la decisión de contratar o no, pero no a quien contratar". Lo cual, a entender de Aldunate, escapa del ámbito protegido de la libertad de contratación, porque de lo contrario, aquello hubiese sido previsto por el legislador cuando, con la

\footnotetext{
$35 \quad$ Ibidem, p. 222.

$36 \quad$ Ibidem, p. 219.

$37 \quad$ Ibidem, p. 219.

38 A este respecto la carta fundamental señala: "Se prohíbe cualquier discriminación que no se base en la capacidad o idoneidad personal, sin perjuicio de que la ley pueda exigir la nacionalidad chilena o límites de edad para determinados casos".
} 
modificación del artículo 2 del Código del Trabajo, ${ }^{39}$ se "restringe la amplia disposición constitucional a criterios específicos de discriminación". ${ }^{40}$

Sin embargo, tal como se señaló anteriormente, la postura de Aldunate no es mayoritaria entre los autores nacionales. En tal sentido, Lizama y Ugarte, afirman, siguiendo el trabajo de la profesora Luz Aldunate, que el tenor de la prohibición del artículo $19 \mathrm{~N}^{\circ} 16$, inciso tercero, "no sólo alcanza a la ley y las autoridades públicas, sino que extiende la obligación de no discriminar a los particulares". ${ }^{41}$

De lo contrario, en opinión de estos autores, si no se hiciera extensiva la prohibición de discriminación entre particulares, se caería en el absurdo de dejar fuera del ámbito protector a la mayoría de los trabajadores que se desempeñan en el sector privado. ${ }^{42}$

La idea esbozada por Luis Lizama y José Luis Ugarte es coherente con la línea de reforzar los argumentos a favor del efecto horizontal o directo de los derechos fundamentales entre particulares. Postura sostenida por estos autores en su libro: "Interpretación y derechos fundamentales en la empresa". ${ }^{3}$

\section{La contraposición de derechos fundamentales graficados en la libertad de trabajo y su protección.}

En el enunciado de la libertad de trabajo y su protección, de la forma en que se encuentra consagrada en el numeral 16 del artículo 19 de la Constitución Política, "existe un claro distanciamiento en lo que respecta al denominado constitucionalismo social". ${ }^{4}$

Tal como señala Pedro Irureta, los integrantes del Consejo de Estado, por medio de la comisión -Ortúzar- encargada de la redacción de la nueva Constitución, "optaron por eliminar toda referencia a un derecho social del estilo del derecho al trabajo, así como a cualquier otra declaración análoga que no diera acción para exigir su cumplimiento". ${ }^{45}$

\footnotetext{
$39 \quad$ Por medio de la ley 19.759 de 2001.

40 ALDUNATE, ob. cit., p. 220.

41 LIZAMA, Luis y UGARTE, José Luis: Interpretación y derechos fundamentales en la empresa. Editorial Jurídica Cono Sur Ltda., Santiago, 1998. p. 231.

42 LIZAMA y UGARTE, ob.cit., p. 232.

43 Esto sin perjuicio de tener en cuenta que este trabajo es de 1998, y que, a la fecha, ambos autores han diferenciado sus derroteros.

44 IRURETA, ob. cit., p. 25.

45 Ibidem, p. 219.
} 
Empero, más que una decisión ideológica, la cual lo es, por cierto, aquella fue una opción económica, si se quiere llamarla así, por cuanto los redactores de la Constitución Política concebían los derechos sociales como prestaciones directas que los ciudadanos exigen y que el Estado debe estar en condiciones de cumplir, situación que quería evitarse. Esta es la razón de por qué el énfasis en materia laboral se encuentra en la autonomía, la libertad de trabajo, de elección y de no discriminación laboral, también, por cierto, en la libertad de afiliación. Cariz economicista más que centrado en su arista protectora.

Bajo este entendido tiene relevancia la definición de orden público económico que realiza Arturo Fermandois, en el sentido de que es "el adecuado modo de relación de todos los diversos elementos de naturaleza económica presentes en la sociedad, que permita a todos los agentes económicos, en la mayor medida posible y en un marco subsidiario, el disfrute de sus garantías constitucionales de naturaleza económica de forma tal de contribuir al bien común y a la plena realización de la persona humana". ${ }^{46}$

Primando claramente el enfoque en la libertad de emprender, a pesar de que, conforme a la atribución de significado que se realiza del precepto constitucional que se analiza ${ }^{47}$ - artículo $19 \mathrm{~N}^{\circ} 16$-, es posible considerar aquella disposición, por un lado, con una dimensión tutelar de los trabajadores y, a su vez, de la libertad propiamente tal respecto de los empleadores.

\section{El cariz tutelar para el trabajador del $19 \mathbf{n}^{\mathbf{0}} 16$.}

En un comienzo existió consenso doctrinario en considerar que "la proclamación constitucional del derecho al trabajo no implica el surgimiento de derechos subjetivos estrictos por parte de los ciudadanos; o deberes del Estado en orden a facilitar puestos de trabajo, sobre todo en un sistema económico basado en la libertad de empresa". ${ }^{48}$ Con todo, sería deber exclusivo del poder público facilitar los medios para cumplir el programa constitucional. Premisa mayoritariamente superada por la doctrina y contradictoria,

46 FERMANDOIS, Arturo: Derecho Constitucional Económico. Regulación, tributos y propiedad, Tomo II. Ediciones Universidad Católica de Chile, Santiago, 2014. p. 29.

47 Entendiendo bajo aquella nomenclatura el ejercicio de la actividad interpretativa, siguiendo metodológicamente en ello a Guastini y, en complemento, a los argumentos interpretativos de Ezquiga, tal como se indicaba al comienzo de este trabajo.

48 IRURETA, ob. cit., p. 28. 
por lo demás, con las propias disposiciones del artículo $19 \mathrm{~N}^{\circ} 16$ cuando establece que el trabajo debe ser compensado con una justa retribución, conforme a la cual claramente el único obligado es el sujeto privado.

A tal respecto, con toda lógica apunta Irureta: "si efectivamente el 'derecho al trabajo' no fue consagrado por temor que éste fuese exigido al Estado, entonces con la misma lógica debería haberse suprimido la referencia a que todo trabajo debe dar origen a una justa retribución ya que en este caso nos encontramos ante un derecho de 'doble cara', porque se hacen valer tanto hacia los poderes públicos como en las relaciones entre particulares". 49

Así las cosas, a pesar de que en el artículo $19 \mathrm{~N}^{\circ} 16$ se entrecruzan derechos de diferente naturaleza, confundiéndose entre derechos civiles y políticos, a modo de ejemplo, esta norma es clave para entender el modelo de relaciones laborales que ostenta la Constitución de 1980, y permite entender el orden público económico y laboral del ordenamiento jurídico chileno. De ahí se dilucida que el derecho del trabajo implica un reconocimiento a la libertad de trabajo y empresa, el pluralismo social, la autonomía colectiva, y la tutela y protección del trabajo. ${ }^{50}$

En tal sentido, más allá de lo interpretable a la luz de la redacción del artículo $19 \mathrm{~N}^{\circ} 16$, se puede afirmar que esta disposición "con una orientación muy similar a la contenida en el antiguo art. 153 de la Constitución de 'Weimar', consagra, además, la protección del trabajo humano". ${ }^{51}$ Protección que posee una aplicación amplia y que implica a todo trabajo productivo. En base a esta disposición constitucional se vislumbra que el trabajo y su protección se constituye "como la base material de la sociedad en torno a la cual se organizan las relaciones sociales y los conflictos propios del sistema productivo". ${ }^{2}$

Situación coherente, además, con "la historia del Estado de derecho, del constitucionalismo democrático y de los derechos humanos que puede ser leída como la historia de una larga lucha contra el absolutismo del poder. Gracias a lo cual, como complementa Luigi Ferrajoli, "se ha ido luego progresivamente reduciendo el absolutismo de los poderes económicos y empresariales, a través de la legislación sobre el trabajo, las garantías de los derechos de los trabajadores y las reglas de tutela de la concurrencia y de la

\begin{tabular}{ll}
\hline 49 & Ibidem, p. 29. \\
50 & Ibidem, p. 30. \\
51 & Ibidem, p. 52. \\
52 & Ibidem, p. 53.
\end{tabular}


transparencia de los negocios.... los derechos fundamentales se han configurado al mismo tiempo como leyes del más débil y como contrapoderes, límites y vínculos a poderes de otro modo absolutos". ${ }^{53}$

Nuestro ordenamiento constitucional no es ajeno a ello, teniendo en cuenta que el artículo $19 \mathrm{~N}^{\circ} 16$ de la Constitución Política protege el trabajo humano, se entiende que el trabajo posee preeminencia como un principio ordenador del ordenamiento jurídico, en tal sentido el titular del trabajo cuenta con una gama de derechos frente al Estado, quien debe protegerlo de intervenciones de terceros que puedan vulnerar sus garantías fundamentales. $^{54}$

Atribuyéndosele significado -es decir interpretando, como ya se explicó- a la disposición analizada en el presente trabajo, en el sentido de entenderla como una norma bidireccional que, por una parte, implica un carácter tuitivo para el trabajador, al ser protegido el trabajo mismo y la libre elección de aquél, la justa retribución y la no discriminación laboral. Mientras que, a su vez, la libertad de trabajo y su protección implica, en conjugación con otros preceptos constitucionales, una esfera de protección constitucional al empleador graficado mediante la libre contratación y por sobre todo la libertad de industria y comercio. Como se verá de forma más detallada en el epígrafe siguiente.

Esta visión, de doble faceta protectora otorgada a la disposición del artículo $19 \mathrm{~N}^{\circ} 16$, se reafirma con lo señalado por Lizama y Ugarte, en el sentido de que "en lo fundamental se protegen dos aspectos: por una parte, la libertad de trabajo, esto es, el derecho de toda persona de no ser forzada a labor, la cual sólo puede ser ejecutada con su consentimiento previo y libre, y, por otra, la libertad de contratación y la libre elección del trabajo, que consiste en la facultad de toda persona de escoger sin sujeción o concurso de otro, el momento, la persona, la labor y las condiciones en que contratará sus servicios laborales, con sujeción a los límites establecidos en la ley". ${ }^{55}$

Libertad de trabajo que, bajo el cariz protector del trabajador, para estos autores implica, primordialmente, la protección frente a la discriminación laboral, en relación con lo establecido en el inciso tercero del artículo 19 $\mathrm{N}^{\circ} 16$ de la Constitución, cuyo análisis ya se esbozó en el presente trabajo.

53 FERRAJOLI, Luigi: "Sobre los Derechos Fundamentales". En: Revista Mexicana de Derecho Constitucional, vol. Julio-diciembre, 2006, N 15. p. 134.

54 IRURETA, ob. cit., p. 53.

55 LIZAMA y UGARTE, ob. cit., pp. $228 \mathrm{~s}$. 


\section{Perspectiva internacional.}

El fenómeno del Estado social de Derecho y del nuevo constitucionalismo es coetáneo a un cambio importante de la legalidad internacional, con planos normativos que expandieron sus límites tradicionales. En palabras de Ferrajoli "gracias a ese embrión de constitución del mundo que está formado por la Carta de la ONU y por sus declaraciones, convenciones y pactos internacionales sobre derechos humanos, también la soberanía estatal externa ha sido jurídicamente limitada, por la sujeción de los Estados al imperativo de la paz y garantía de los derechos humanos establecidos en esas cartas internacionales". ${ }^{56}$

En dicho ámbito, como piedra angular tenemos la Declaración Internacional de Derechos Humanos de la ONU, considerando que, como asevera Francisco Ostau de Lafont, "el derecho laboral está representado en todas las declaraciones y principios sobre los derechos humanos" $" 57$. Por su parte, bajo el alero del sistema interamericano y de la OEA, asimismo, existe un nutrido catálogo de tratados internaciones -ratificados por Chile y cuya naturaleza de derechos humanos es de perogrullo- que se refieren específicamente a la protección del trabajo. Sin embargo, previamente hay que considerar la organización y regulación específica en materia laboral, por cuanto -como complementa Ostau de Lafont- "antes de la expedición de Declaración de Derechos Humanos de la Organización de Naciones Unidas (ONU) de 1948, se habían expedido convenios de la OIT desde 1919, como una manifestación de la protección del hombre y, sobre todo, de la concepción de justicia social. De aquí que todos los convenios de la OIT tengan como objetivo el logro de estos principios, enmarcados dentro de los derechos humanos, que van a surgir posteriormente con la creación de la Naciones Unidas" 58 .

Cabe referirse, en relación con el presente análisis, a la relevancia que posee el Pacto Internacional de Derechos Económicos, Sociales y Culturales adoptado por la asamblea general de la ONU el 19 de diciembre de 1966, suscrito por Chile el 16 de septiembre de 1969 y promulgado el 28 de abril de $1989^{59}$.

\footnotetext{
$56 \quad$ FERRAJOLI, ob. cit., p. 115.

57 OSTAU DE LAFON (2015) p. 51.

58 OSTAU DE LAFON, Francisco: El Derecho Internacional Laboral. Editorial Universidad Católica de Colombia, Bogotá, 2015. p. 51.

59 Decreto Ley $\mathrm{N}^{\circ} 326$, que promulga el Pacto Internacional de derechos económicos, sociales y culturales el 28 de abril de 1989.
} 
Específicamente cabe rescatar, por su coherencia en relación con la disposición que se analiza -referido a la libertad de trabajo y su protección- el artículo 7 del refrendado Pacto Internacional, cuando señala: "Los Estados partes en el pacto reconocen el derecho de toda persona al goce de condiciones de trabajo equitativas y satisfactorias". Enumerando una serie específica de derechos que regulan mínimos básicos y protección al trabajador tanto en su derecho individual como colectivo.

Norma internacional que adquiere relevancia teniendo en cuenta la reforma constitucional, del 17 de agosto 1989, realizada al inciso segundo del artículo 5 de la Constitución Política ${ }^{60}$. A este respecto Jorge Mario Quinzio señala que "esta reforma tiene relevante importancia, ya que la defensa de los derechos humanos no sólo tendrá como base la legislación nacional, sino también los documentos internacionales como la declaración Universal de Derechos Humanos, de 10 de diciembre de 1948; el Pacto Internacional de derechos económicos sociales y culturales, de 19 de diciembre de 1966; el Pacto Internacional de derechos Civiles y Políticos, de 1966; la convención Americana sobre derechos humanos 'Pacto San José de Costa Rica, de 22 de noviembre de 1966" ${ }^{\prime 1}$. Reforma muy destacada por la doctrina nacional porque, como a su vez aseveran Cecilia Medina y Claudio Nash, "se considera casi uniforme que la enmienda ha elevado los tratados internacionales que consagran derechos humanos a rango constitucional" 62 .

Consecuencia de lo cual, al momento de analizar la libertad de trabajo y su protección, su lectura debe comprenderse armónica y complementaria con el reformado inciso segundo del artículo 5 de la Constitución Política. La relevancia de esta modificación radica en que ella precisamente tenía como finalidad que nuestro ordenamiento constitucional considerara mínimos internacionales en materia de derechos humanos, tal como fue el caso del Pacto Internacional antes dicho - promulgado como ley de la República

$60 \quad$ "El ejercicio de la soberanía reconoce como limitación el respeto a los derechos esenciales que emanan de la naturaleza humana. Es deber de los órganos del Estado respetar y promover tales derechos, garantizados por esta Constitución, así como por los tratados internacionales ratificados por Chile y que se encuentren vigentes".

61 QUINZIO, Jorge Mario: Tratado de derecho Constitucional. Tomo I. Editorial Lexis Nexis, Santiago, 2006. p. 257.

62 NASH Claudio y MEDINA, Cecilia: "Manual de derecho internacional de los derechos humanos". 2003. Disponible en: ttps://www.fundacionhenrydunant.org/images/ stories/biblioteca/derechos_humanos/MEDINA_C._y_NASH_C._2003.Manual_de_ Derecho_Internacional_de_los_DDHH.pdf. Fecha de consulta: 13 de marzo de 2018.p. 47. 
el mismo año de esta reforma, específicamente el 27 de mayo de $1989^{63}$-, y cuya relación con el artículo $19 \mathrm{~N}^{\circ} 16$ de la Constitución Política es manifiesta, especialmente en lo referido a la protección detallada y específica al trabajo remunerado que realiza el Pacto. Análisis al que se arriba considerando una interpretación teleológica de las disposiciones analizadas, que siguiendo a Ezquiga implica comprender un significado apelando a la finalidad del precepto ${ }^{64}$.

Por cuanto, en concordancia con la eficacia inmediata de los derechos fundamentales de los trabajadores que se asevera en este artículo, una disposición contenida en un tratado internacional de derechos humanos, ratificado por Chile y que se encuentre vigente, es susceptible de aplicarse directamente por el juez llamado a resolver un caso concreto donde el ejercicio de subsunción le permita concluir aquello.

Corolario de lo anterior, y de la interpretación sistémica de la Constitución Política, la circunstancia de que la protección de un derecho fundamental de tal relevancia, como lo es el trabajo humano, se haya redactado de forma tan ambigua, que incluso a alguna parte de la doctrina le genera dudas sobre su protección propiamente tal, no es óbice para desconocer su protección. De hecho, la regulación expresa de la protección del trabajo ha sido uno de los pilares del estado social de derecho, y la consagración de los derechos sociales -conocidos como de segunda generación- fundamentales.

"Una expansión similar -como analiza Ferrajoli- se encuentra por lo demás en la lógica misma del constitucionalismo. La historia del constitucionalismo es la historia de la progresiva extensión de la esfera de los derechos: de los derechos de libertad en las primeras declaraciones y constituciones del siglo XVIII, al derecho de huelga y a los derechos sociales en las constituciones del siglo XX...una historia no teórica sino social y política, dado que ninguna de las diversas generaciones de derecho ha caído del cielo, sino que todas han sido conquistadas por otras tantas generaciones

63

A su vez, es importante recordar que estas disposiciones, junto a otras regulaciones constitucionales, el mismo año fueron objeto de importantes reformas a la Constitución Política. Modificaciones cuya interpretación adquiere coherencia con el texto primigenio, si se considera que aquellas reformas las realizó el mismo régimen 'ideólogo' de la Constitución de 1980, por cuanto deben entenderse congruentemente integradas con todo el catálogo de derechos fundamentales consagrados en el artículo 19 de la Constitución Política.

64

EZQUIAGA, ob. cit., p. 95. 
de movimientos de lucha y de revuelta: primero liberales, luego socialistas, feministas, ecologistas y pacifistas" $"$.

\section{La esfera protectora de las libertades del empresario.}

En consonancia con lo señalado precedentemente, abordando ahora la esfera de la protección constitucional del empleador, la libertad de contratación implica un reconocimiento "tanto para los trabajadores dependientes como para los empresarios, pero no cabe duda que en el ámbito laboral este derecho cobra mayor sentido para el empleador que tiene una titularidad sobre la actividad productiva" $"$.

De tal modo, para el empleador la libre contratación se materializa como un derecho vinculado a la libertad de empresa, en el sentido de que él posee un poder amplio para contratar, con la única limitante de que debe ceñirse a criterios de idoneidad y capacidad del trabajador. Así mismo, en dicha línea Arturo Fermandois resalta que éste es el enfoque del orden público económico de nuestra regulación constitucional, al aseverar que "la doctrina constitucional moderna enfatiza el principio rector de que uno de los elementos fundamentales del orden público lo constituye la libertad misma de contratación"; agregando Fermandois que el eje de la Constitución de 1980 radica en la libertad económica, autonomía que tendría ciertos límites, "pero conceptual y jerárquicamente el constituyente ha colocado primero la libertad de emprender actividades económicas y luego los límites de la misma. De este modo las limitaciones son la excepción y la libertad la regla general" ${ }^{\prime \prime}$.

Claramente estamos en presencia de una esfera de autonomía, lo que no quiere decir "que la constitución haya consagrado el principio de la autonomía de la libertad en materia laboral" 68 . Porque las relaciones laborales deben ceñirse a las normas del ramo donde existen exigencias de irrenunciabilidad en lo que respecta a derechos mínimos consagrados por el orden jurídico-laboral, de lo contrario, "el mero consentimiento del trabajador sería suficiente para asegurar un conjunto de intereses que terminan afectando al orden social" ${ }^{\prime 9}$. Por su parte, la libertad de empresa, abordado conforme a la disposición del artículo $19 \mathrm{~N}^{\circ} 16$, en su inciso cuarto, implica

\begin{tabular}{ll}
\hline 65 & FERRAJOLI, ob. cit., p.116. \\
66 & IRURETA, ob. cit., pp. 61 s. \\
67 & FERMANDOIS, ob. cit., p.30. \\
68 & IRURETA, ob. cit., p. 63. \\
69 & Ibidem, p. 63.
\end{tabular}


uno de los elementos más tradicionales de la libertad económica, concebida tradicionalmente, a saber: "Ninguna clase de trabajo puede ser prohibida, salvo que se oponga a la moral, a la seguridad o a la salubridad públicas o que lo exija el interés nacional y una ley lo declare así "70.

A su vez, esta disposición guarda armonía con otra similar como es la establecida en el numeral 21 del mismo artículo 19, cuando ésta señala: "el derecho a desarrollar cualquier actividad económica que no sea contraria a la moral, al orden público o a la seguridad nacional, respetando las normas legales que la regulen" "71, atribuyéndoseles un significado interpretativo recíproco, a la luz de la simple, y además obvia, lectura de ambas disposiciones, considerando el argumento sistemático en sentido estricto, como nos ilustra Francisco Ezquiga ${ }^{72}$.

Ambos preceptos condensan una concepción de la libertad económica configurada por antonomasia a partir de la revolución industrial, la cual posee una protección desde el constitucionalismo chileno decimonónico, al ser una "norma que viene desde la constitución de 1833 y que busca reafirmar las exigencias de la sociedad liberal en contra las reglamentaciones propias del sistema corporativo imperante hasta el siglo XVIII" 73 .

Escenario nacional, anteriormente descrito, que no es aislado y que se condice con el panorama político y económico imperante en todo el constitucionalismo occidental del siglo XIX. Sistema económico que consagró la libertad de industria y comercio como pilar fundamental del Estado liberal, y cuya inspiración se encuentra en el artículo 13 de la Declaración de los Derechos del Hombre y del Ciudadano, emanada del seno de la revolución francesa, al establecer: "ningún tipo de trabajo, de cultura o de comercio puede ser prohibido a la actividad de los ciudadanos'. En el fondo, en el Estado liberal esta garantía se concebía como un derecho de 'defensa o de omisión' oponibles al poder público"774.

En tal sentido, la actual Carta Fundamental chilena no posee un origen, en su contenido de orden público económico, que sea disonante con tendencias imperantes a nivel internacional.

Pues bien, bajo una arista diversa a la que se ha venido analizando hasta ahora, el profesor Claudio Palavecino sostiene que con el tenor de la dis-

\footnotetext{
$70 \quad$ Constitución Política de la República de Chile, artículo 19 Nº 16 , inciso cuarto.

71 Constitución Política de la República de Chile, artículo 19 №21, inciso primero.

72 EZQUIAGA, ob. cit., p. 93.

73 IRURETA, ob. cit., p. 91.

74 Ibidem, p. 91.
} 
posición legal, al señalar "y su protección", se ha querido ver por parte de la doctrina, partiendo por el tempranero trabajo de Luz Bulnes, como "un mandato de la Constitución de protección no solo a la libertad de trabajo sino que también al trabajo mismo"75.

Según esta concepción -como la argumenta Palavecino para, acto seguido, criticarla-, el artículo $19 \mathrm{~N}^{\circ} 16$ implicaría dos enunciados de naturaleza 'ius fundamental', como es, en primer lugar, la 'libertad' de trabajo' propiamente tal (por llamarla de algún modo), y que implica un ámbito tutelar que se satisface precisamente con la abstención del Estado; mientras que, por otro lado, se establecería una protección del trabajo que requiere, a contrario sensu, de la intervención estatal que "sin una específica forma de exigibilidad individual -puesto que, como se dijo, no hay técnicamente un 'derecho al trabajo'- pero que cumpliría sin embargo una significativa función habilitante de la intervención estatal, ofreciendo cobertura constitucional a la legislación laboral" ${ }^{176}$.

Para Palavecino, esta 'interpretación canónica' del artículo 19 № 16, obedece a una visión más tradicionalista del derecho del trabajo, y que se entendería porque el enunciado 'la libertad de trabajo y su protección' refleja "una tensión permanente entre dos fuerzas opuestas: la libertad de trabajo por un lado y el deber de protección del trabajo por el otro atendida la manifiesta contradicción entre lo que la Constitución exige del Estado en uno y otro caso, a saber: abstención versus intervención" "77. La contradicción radica en el hecho de que en la medida que una acción protectora tiene injerencia en la libertad redundando en su limitación, mientras que, a su vez, una ampliación de la autonomía de la voluntad se interpretará como falta de regulación protectora.

Claramente, para este autor, el enunciado del artículo $19 \mathrm{~N}^{\circ} 16$ consagrado en nuestra carta fundamental debe ser interpretado desde la perspectiva de inclinarse por la libertad de trabajo 'propiamente tal' más que, a la inversa, por la protección del trabajo mismo. Palavecino llega a dicha conclusión, en coherencia con la visión inherente en el seno político al momento de surgir la Constitución Política, "sobre todo si se tiene en cuenta que la Constitución de 1980 vino precisamente a instaurar un nuevo paradigma de orden público económico donde la libertad es el gran bien

$75 \quad$ PALAVECINO Claudio: "La libertad de trabajo y su protección constitucional. Nueva lectura”, Revista laboral chilena, vol. 8, N²19, 2013. p. 79.

76 Ibidem, p. 80.

77 Ibidem, p. 80. 
jurídico a proteger" "78. Por lo mismo, el mandato al legislador va en la línea de no suprimir ni "limitar severamente" la autonomía de la voluntad en el marco de las relaciones laborales ${ }^{79}$.

Además, siguiendo con Claudio Palavecino, incluso en el caso de que se acepte la concepción 'decimonónica' sobre la protección del trabajo, entendido como independiente respecto de la libertad de trabajo, en ningún caso la Constitución señala la forma cómo el Estado debería realizar aquella regulación y, menos aún, implica que deba entenderse la misma en contraposición, vale decir de una forma conflictiva, con la libertad de trabajo ${ }^{80}$.

\section{Facultades disciplinarias del empleador.}

Dentro del ámbito del derecho consistente en la libertad para ejercer cualquier actividad económica, el empleador se encuentra imbuido por una serie de facultades que permiten desempeñar su actividad productiva; de las cuales, potencialmente, pueden surgir posibles colisiones con los derechos fundamentales de los trabajadores.

En el contrato de trabajo coexisten derechos recíprocos que van más allá de los tradicionales derechos y obligaciones prestacionales y de remuneración que son el objeto y causa del mismo. Estos derechos 'anexos' son, "de una parte, los derechos del empleador para una adecuada prestación de servicios en perspectiva del cumplimiento de los fines de la empresa con las obligaciones del trabajador. De otra parte, están los derechos del trabajador en vista del trabajo a realizarse y su involucramiento personal, con las respectivas obligaciones empresariales" ${ }^{\prime 1}$. Conviviendo de tal modo derechos para ambas partes en la relación laboral.

Dentro de los derechos del empleador, siguiendo a Irene Rojas, se encuentran: 'la potestad jurídica de mando'; ‘el poder de dirección'; 'el poder disciplinario'; y el 'ejercicio del ius variandi' ${ }^{82}$.

En tal entendido, de todas las manifestaciones que pueden adoptar estos derechos del empleador, el presente análisis se centra en la potestad disciplinaria del empleador. Esto considerando que aquella es la facultad que, por un lado, mayormente puede vulnerar los derechos de los trabajadores,

\footnotetext{
$78 \quad$ Ibidem, p. 81 .

$79 \quad$ Ibidem, p. 81.

$80 \quad$ Ibidem, p. 82.

81 ROJAS, Irene: Derecho del Trabajo. Derecho individual del Trabajo. Editorial Thomson Reuters, Santiago, 2015. p. 290.

82 Ibidem, pp. 293-297.
} 
como también, porque es un derecho que por antonomasia refleja esta dualidad, postulada en el presente trabajo, respecto de la contraposición de intereses derivados de un análisis del artículo $19 \mathrm{~N}^{\circ} 16$, que para el empleador se manifiesta en el poder que éste tiene en la relación laboral originado en su derecho fundamental de libertad de trabajo (bajo esta doble perspectiva que se plantea en este análisis) y el derecho para ejercer cualquier actividad económica.

Respecto del 'poder disciplinario', Irene Rojas señala que es "la potestad que el ordenamiento jurídico laboral entrega al empleador con el objeto de mantener una disciplina y orden tal que permita el adecuado funcionamiento de la actividad laboral" $"$.

En tal sentido, inherentemente estas facultades, según Irene Rojas, se expresarían, primero, en el Reglamento Interno de la empresa, regulado en el artículo 154 del Código del Trabajo y, por otro lado, en el despido disciplinario del cual está facultado el empleador conforme al artículo 160 del mismo cuerpo legal ${ }^{84}$.

En virtud del cual, refiriéndonos específicamente a esta facultad disciplinaria mientras está vigente el vínculo laboral, vale decir el reglamento interno, de éste cabe señalar que "es, en una frase, la ley de orden interno de la empresa, dictada por el acreedor del trabajo" ${ }^{85}$. Es corolario de la facultad de mando del empleador y refleja su poder de dirección, no obstante aquello, Thayer y Novoa señalan que históricamente su origen y justificación no se encuentra en un resguardo de las facultades disciplinarias del empleador, sino que por el contrario, el reglamento interno se establece:

“a) Como una 'autolimitación' del poder de mando del empresario; b) como potestad de 'autonormación' colectiva que regula y en parte sustituye a los contratos individuales; c) como medida de seguridad y publicidad y d) como medida de simplificación administrativa, pues, ante la imposibilidad de celebrar con cada trabajador un contrato con tales estipulaciones, "el reglamento entra a señalarles a todos condiciones comunes" $"$.

Así las cosas, este sería el motivo de por qué, originalmente en Francia y Bélgica, se dictaron leyes que obligaron a los empleadores a establecer

\footnotetext{
$83 \quad$ Ibidem, p. 295.

84 Ibidem, p. 295.

85 THAYER, William y NOVOA, Patricio (2015): Manual del Derecho del Trabajo. Tomo IV. Octava Edición. Editorial Jurídica de Chile, Santiago, 2015. p. 87.

$86 \quad$ Ibidem, p. 87.
} 
reglamentos internos en sus empresas ${ }^{87}$. No obstante, mayoritariamente la doctrina nacional ha considerado como esencia y fundamento del reglamento interno la manifestación del poder disciplinario del empleador. Facultad que, como es lógico, no es absoluta y posee su más claro límite en los derechos fundamentales de los trabajadores.

En esta línea, "no cabe duda alguna de que esta potestad disciplinaria constituye una de las mayores expresiones de poder privado que el derecho sanciona. Implica una especie de poder de policía, pero en manos de un particular: el empleador" $"$.

A tal respecto, Sergio Gamonal junto a Catherine Guidi realizan un interesante paralelo de esta facultad potestativa con el derecho de familia, en el marco de las tradicionales facultades "disciplinarias" que el hombre ha poseído; a modo de ejemplo, en "el antiguo art. 233 del Código Civil establecía la facultad del padre de corregir y castigar moderadamente a sus hijos e, incluso, imponerles la pena de detención hasta por un mes en un establecimiento correccional" $"$. Si bien muchas de estas normas han sido derogadas, el meollo de esta normativa, en opinión de autores como Couso, que cita Gamonal, es que sobresale un poder social que al Estado le interesa que el padre preserve en un ámbito privado importante como es el núcleo familiar ${ }^{90}$.

"El estado no solo quiere reconocer un ámbito de dominio privado al padre de familia, donde éste 'gobierna' sino también alcanzar objetivos políticos a través de ese reconocimiento, gobernando a la familia y gobernando a los individuos a través de la familia", como indica Gamonal siguiendo a Donzelot ${ }^{91}$.

Estrechamente vinculado a lo anterior, el poder disciplinario del empleador surge en un paradigma imbuido por el avance arrollador de la sociedad industrial, que involucra un cambio radical en las formas de producción y de trabajo. Situación que es consecuencia de un cambio aún mayor en la lógica del capitalismo, que pasa de ser 'bursátil' de los siglos XVI y XVII, expresada, por ejemplo, en letras de cambio, a un capitalismo expresado en la acumulación de 'stocks', en los siglos XVIII y XIX, de máquinas

\footnotetext{
$87 \quad$ Ibidem, p. 87.

88 GAMONAL, Sergio y GUIDI, Catherine: Manual del contrato de trabajo. Editorial Thomson Reuters, Santiago, 2012. p. 100.

89 Ibidem, p. 100.

$90 \quad$ Ibidem, p. 101.

$91 \quad$ Ibidem, p. 101.
} 
y materias primas. Lo cual conlleva, necesariamente, la necesidad de seguridad y resguardo de los almacenes donde se conserva esta riqueza, vale decir que, por lo expuestas que se encuentran, hay que evitar una posible 'depredación' de las mercancías, "el gran problema del poder en esta época es instaurar mecanismos de control que permitan la protección de esta nueva forma material de fortuna" como señala Foucault, citado por Gamonal ${ }^{92}$.

Como corolario de lo anterior, a nivel de la relación laboral, este control social se manifiesta por medio de la potestad disciplinaria, la cual "dota de autoridad al empleador dentro de la empresa; se deja en claro quién manda"93. Sin embargo, dicha facultad está sujeta a límites que, según Gamonal, serían el que viene de la autonomía colectiva (principalmente por la negociación colectiva y el arma de la huelga) y por el nivel proteccionista de la ley laboral ${ }^{94}$.

A tal respecto, Luis Lizama señala que la facultad disciplinaria es manifestación de los numerales 21 y 24 de art. 19 de la Constitución Política, en lo relativo a la libertad para desarrollar cualquier actividad económica y al derecho de propiedad; así las cosas, esta facultad "tiene por objeto mantener el orden de los trabajadores al interior de la organización y se dirige a la corrección de las conductas contrarias a la disciplina laboral"95.

Mientras que Sergio Gamonal estima como discutible el correlato constitucional del poder disciplinario, considerando cuestionable que un poder de tal naturaleza esté amparado en el derecho de propiedad, sino que más bien debe entenderse que se trata de una facultad organizativa del empleador reforzada por el Código del Trabajo ${ }^{96}$. Así, Gamonal señala: "Estimamos discutible el fundamento constitucional para un poder punitivo privado como el descrito. Por un lado, hay consideraciones prácticas más que constitucionales, dado que sin este poder probablemente el contrato no se podrá ejecutar el sistema de producción industrial podría llegar a ser inviable. En este contexto, quizás es posible sostener que el derecho a la libre iniciativa económica puede sustentar este poder disciplinario"97.

De lo anterior se desprende que el cuestionamiento que realiza Gamonal sobre la circunstancia de que nuestro ordenamiento jurídico regule

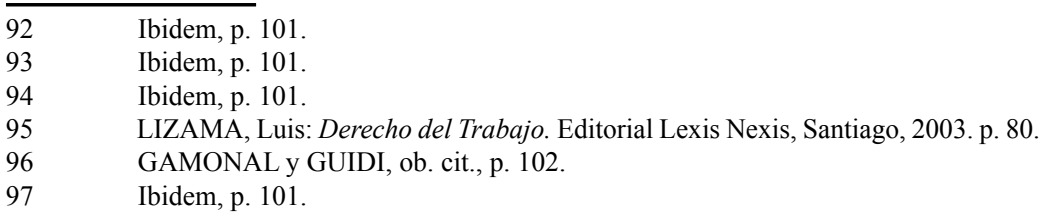


en el ámbito constitucional un 'poder punitivo' para el empleador, puede comprenderse como un acertado cuestionamiento al trasfondo político que esta situación simboliza. Sin embargo, parece difícil soslayar el correlato constitucional de una clara manifestación de su libertad de empresa, como el mismo Gamonal termina reconociéndolo. Además, el hecho de que el poder disciplinario se encuentre regulado en la legislación laboral, no es óbice para descartar la fuente constitucional del mismo, en el sentido de que la carta constitucional menciona un catálogo de derechos a proteger -como es el derecho de propiedad y el de libertad de empresa- y después queda entregada a la ley específica su regulación.

El presente análisis va en la línea de lo argumentado por Lizama en el sentido de que este poder disciplinario tiene un origen en un precepto constitucional y que se manifiesta en la regulación realizada por el Código del Trabajo, lo cual permite que el empleador establezca un régimen de sanciones aplicables a los trabajadores en caso de infracciones, así como un procedimiento que hace posible determinar responsabilidades y aplicar tales castigos ${ }^{98}$.

Es incuestionable que estamos en presencia de una facultad importante del empleador, cuyo ejercicio no puede quedar a su libre arbitrio. Estas medidas deben poseer un catálogo acotado y predeterminado por la ley al empresario. Porque, tal como señala Raúl Fernández, "debido a que el ejercicio del poder disciplinario constituye un acto de autotutela privada, el reconocimiento de la posibilidad concreta de aplicar por el empleador una sanción a sus trabajadores por transgresión a la disciplina laboral ha de provenir de la ley o de una fuente que se remita a la ley"

Consecuencia de lo cual, zanjado el tema de que las facultades disciplinarias del empleador poseen un sustento constitucional, las aristas del mismo deben poseer una regulación precisa en la legislación laboral. A su vez, fruto de esta misma legislación, y gracias a progresivas modificaciones parlamentarias, se desprenden los correlativos derechos de los trabajadores que permiten el resguardo de sus garantías constitucionales.

En tal sentido, "una de las disposiciones más significativas dentro del tema de los derechos fundamentales de los trabajadores corresponde al nuevo inciso final del artículo 154 del Código del Trabajo en orden a señalar

$98 \quad$ Ob. cit., p. 80.

99 FERNÁNDEZ, Raúl: "Poder disciplinario del empleador: Configuración jurídica de la falta laboral cometida por el trabajador dependiente". En: Revista lus et praxis, vol. 21, $\mathrm{N}^{\circ} 2,2015$. p. 273. 
ciertos requisitos en las medidas de control por parte del empleador, y que se refiere en términos amplios a cualquier forma de control implementada por la empresa, sea que se trate de un test de drogas o de alcohol, revisión de personas o de casilleros, cámaras de vídeo o televisión, etcétera" ${ }^{100}$.

Al tenor de lo anterior, el inciso final del artículo 154 señala: "las obligaciones y prohibiciones a que hace referencia el número 5 de este artículo, y en general, toda medida de control, sólo podrán efectuarse por medios idóneos y concordantes con la naturaleza de la relación laboral y, en todo caso, su aplicación deberá ser general, garantizándose la impersonalidad de la medida, para respetar la dignidad del trabajador"101.

En esta materia Ugarte rescata un extracto de la que él denomina "la sentencia inaugural del tema de los derechos fundamentales inespecíficos en Chile, ya que la Corte Suprema, conociendo de la impugnación de un sistema de cámara de televisión utilizado para efectuar seguimientos de los trabajadores, señaló que dentro del recinto laboral, constituido por el ámbito de actividad propio de los empleados, los trabajadores tienen derecho a la privacidad o intimidad, manifestándose ello en el deseo de, como en el caso de autos, se mantenga en la esfera laboral y sindical las actividades realizadas por ellos, sin que en él se permita la intromisión de terceros. Lo anterior puede ser compatibilizado con la existencia de un sistema de vigilancia y protección en el recinto laboral, pero éste no debe estar desviado de los fines que justificaron su instalación", que son sólo protección empresarial” (Corte Suprema, 05.01.2006, Rol No 5.234/2005) ${ }^{102}$.

\section{Conclusiones}

El contrato de trabajo es un terreno donde, efectivamente, conviven, pero no necesariamente colisionan, derechos fundamentales contrapuestos.

El conflicto es latente, por cierto, como en cualquier orden de cosas donde existen intereses diversos, como son los del empresario y los de los trabajadores, pero se avizora que tienen un objetivo meridianamente común: poseer relaciones laborales armónicas, por cuanto en la medida que se logra un objetivo común se satisfacen los intereses recíprocos de ambas partes. A modo de ejemplo, reduciendo esta vez el análisis a la lógica eco-

$100 \quad$ UGARTE, José Luis: El nuevo derecho del Trabajo. Tercera edición. Editorial Legal Publishing, Santiago, 2011. p. 126.

101 Código del Trabajo, artículo 154, último inciso.

102 UGARTE, El nuevo derecho, ob. cit., p. 127. 
nomicista que prima en la negociación colectiva, en el plano de negociación inserta en una empresa con utilidades crecientes, lógicamente dichos réditos se reflejarán en una mayor expectativa económica y de beneficios exigidos por los trabajadores a la parte patronal. Se quiera o no, en el contexto de una economía de mercado donde fluctúan las relaciones laborales, existe una dependencia recíproca de sus actores.

Empero, estos intereses contrapuestos son susceptibles de resquebrajarse y colisionar. Situación comprensible considerando que se encuentran en tensión derechos fundamentales que interactúan en el mismo escenario y que poseen intereses contrapuestos. Tal como se delineó en un comienzo de la investigación, estamos en presencia de un problema de equilibrio entre derechos de igual relevancia jurídica.

Discusión que sólo ha tenido cabida con un cambio importante del paradigma político social. Previamente, el origen mismo del derecho laboral tiene su origen en la visualización de que las relaciones laborales, tras el surgimiento avasallador de la sociedad industrial, no podían regularse bajo la lógica de la autonomía de la voluntad que gobierna el derecho privado común. Resultando imperioso que surgiera una legislación que garantizara mínimos de respeto para los derechos de los trabajadores.

En el siglo XX, junto con el cambio del Estado liberal al Estado social de derecho, emerge una protección social más robusta, teniendo cabida, asimismo, la constitucionalización del derecho laboral. Es en este contexto, entendiéndose que existen esferas privadas que ejercen tanto poder como los órganos públicos y su potencialidad vulneradora de derechos es tanto o más concreta, surge la teoría -que no es pacífica, por cierto- de la eficacia horizontal de los derechos fundamentales. A raíz de lo cual, tal como el Estado, un ente privado como es la empresa pude afectar derechos fundamentales de un trabajador y, del mismo modo como se realiza respecto del Estado, se le puede exigir el restablecimiento del derecho recurriendo inmediatamente al catálogo constitucional. De tal modo, se justifica plenamente la eficacia inmediata de los derechos fundamentales y la horizontalidad de los mismos.

Así las cosas, en el análisis llegamos a nuestra actual carta constitucional, la cual se hace eco de una serie de derechos que podríamos denominar como sociales, pero abordados con una redacción ambigua y equívoca, no simplemente por error, sino más bien por temor de que gran parte de éstos se entendieran como derechos subjetivos exigibles directamente al Estado. El artículo $19 \mathrm{~N}^{\circ} 16$ es hijo de esta concepción temerosa. 
Aquella disposición es la que mejor grafica el cruce y tensión latente que existe entre derechos fundamentales tanto del trabajador como del empresario, en ella se concatenan derechos y obligaciones recíprocas para ambas partes de la relación laboral.

Si bien es atingente lo apuntado por los autores que, en coherencia con el contexto político económico embrionario de la Constitución de 1980, leen esta norma como protectora exclusivamente de la libertad de emprender, pese a ello, debe comprenderse que la actividad interpretativa posee diferentes herramientas, donde la historia fidedigna de la ley -o de la Constitución en este caso- es una de ellas y no necesariamente la primera, además, en esta disposición el tenor literal de la ley tampoco es claro. En dicho entendido, la doctrina mayoritariamente ha visto en esta normativa ambigua no sólo la protección a la libertad de trabajo, sino también al trabajo mismo.

Es fundamental para arribar a la consideración de que estamos en presencia de una norma bifronte, junto al análisis de la literatura estudiada y a las diferentes perspectivas doctrinarias, el haber realizado el ejercicio interpretativo consistente en 'atribuir significado' a esta disposición -utilizando las palabras de Guastini, tal como se optó en el comienzo de este trabajo- comprendiendo, además, que la concepción de la libertad de trabajo y su protección no se limita a la regulación del artículo $19 \mathrm{~N}^{\circ} 16$. Motivo por el cual, su análisis implica un abanico de disposiciones que permiten llegar a esta comprensión teniendo en cuenta una perspectiva integradora -asilándonos igualmente en la argumentación sistemática en sentido estricto, recogida de Ezquiaga-, como manifestación de la libertad del empleador se complementa con el numeral 21 del mismo artículo 19 de la Constitución Política.

A su vez, interpretando dicha disposición bajo aquella perspectiva integradora se comprende que los derechos fundamentales del trabajador poseen también un catálogo más amplio, que es concomitante a la protección misma del trabajo, impregnada, con la regulación que otorgan los tratados internacionales de derechos humanos que -al alero del artículo 5 y la interpretación 'teleológica', como se explicó, de la reforma a su inciso segundorobustece el catálogo de derechos fundamentales regulado en el artículo 19 de la Constitución Política.

Consecuencia de lo cual, perfectamente se puede entender el artículo 19 $\mathrm{N}^{\mathrm{o}} 16$ como una 'norma eje' en el que convergen derechos fundamentales de ambas partes de la relación laboral. Además, parecería ilógico concluir que se excluye la protección de la parte trabajadora, siendo que ella es precisamente la destinataria de la retribución que origina la prestación de servicios. 
Aseveración complementaria, bajo la arista protectora del empleador, con el análisis realizado a algunos matices de su poder disciplinario, en el entendido de que es una facultad derivada de sus garantías constitucionales. El cual, además, por antonomasia refleja el poder que una parte -el empresariodetenta en una relación de subordinación y dependencia y que, por lo mismo, es muy susceptible de vulnerar los derechos de su contra parte: el trabajador. Por lo mismo, en el seno de su regulación en el Código del Trabajo, a raíz de modificaciones a la disposición que regula el reglamento interno, se han otorgado herramientas a los trabajadores para poner cortapisas a esta facultad empresarial. Robusteciéndose, asimismo, los derechos fundamentales de los trabajadores con el procedimiento de tutela laboral, como también, mediante la sucesiva ratificación de tratados internacionales sobre derechos humanos. Donde, si bien no se analizaron por no ser objetivo del presente estudio, también poseen gran relevancia los Convenios de la OIT.

En definitiva, son variadas las disposiciones que consagran en la Constitución Política los derechos fundamentales tanto de trabajadores como de empresarios, sin embargo, como se ha podido apreciar, sin querer tal vez, el 19 $\mathrm{N}^{\mathrm{o}} 16$ se transformó en una norma bifronte $\mathrm{o}$, dicho en otras palabras, en una disposición bisagra de las ambigüedades que intenta proteger nuestra Carta Magna, y cuyas reformas no se han esforzado en esclarecer. Lo concreto, siendo lo que se logra dilucidar con esta investigación, es que la disposición estudiada cobija dos expresiones, las que deben entenderse como protectoras de ambas partes de la relación laboral. Es, en definitiva, una amalgama de protección de los derechos fundamentales del trabajador y del empresario.

\section{Bibliografía.}

ALEXY, Robert: "La fórmula del peso", en Carbonell, Miguel (edit.): El principio de proporcionalidad en la interpretación jurídica. Editorial Librotecnia, Santiago, 2010. 17-52.

ALDUNATE, Eduardo: Derechos Fundamentales. Editorial Thomson Reuters, Santiago, 2008.

CAZZETA, Giovanni: Estado, Juristas y Trabajo. Itinerarios del Derecho del Trabajo en el siglo XX. Editorial Marcial Pons, Madrid, 2010.

EZQUIAGA, Francisco: "Argumentos interpretativos y postulado del legislador racional". 1994. Disponible en: http://www2.scjn.gob.mx/red2/ investigacionesjurisprudenciales/seminarios/20- seminario-jurisprudencia/ 
modulo-vii/04francisco-ezquiaga-argumentos-interpretativos.pdf. Fecha de consulta: 19 de marzo de 2018.

FERMANDOIS, Arturo: Derecho Constitucional Económico. Regulación, tributos y propiedad, Tomo II. Ediciones Universidad Católica de Chile, Santiago, 2014.

FERNÁNDEZ, Raúl: "Poder disciplinario del empleador: Configuración jurídica de la falta laboral cometida por el trabajador dependiente". En: Revista lus et praxis, vol. 21, N², 2015. pp. 267-316.

FERRAJOLI, Luigi: "Sobre los Derechos Fundamentales". En: Revista Mexicana de Derecho Constitucional, vol. Julio-diciembre, 2006, №15. pp. 114-136.

FOUCAULT, Michel: La verdad y las formas jurídicas. Editorial Gedisa, Barcelona, 2010.

GAMONAL, Sergio: Fundamentos de Derecho Laboral. Tercera edición. Editorial Thomson Reuters, Santiago, 2012.

GAMONAL, Sergio y GUIDI, Catherine: Manual del contrato de trabajo. Editorial Thomson Reuters, Santiago, 2012.

GREZ, Sergio: De la regeneración del pueblo a la huelga general. Génesis y evolución histórica del movimiento popular en Chile (1810-1890). Segunda edición. Editorial Ril, Santiago, 2007.

GUASTINI, Riccardo: Estudios sobre interpretación jurídica., Editorial del Instituto de investigaciones jurídicas de la UNAM, México, D.F., 1990.

IRURETA, Pedro: Constitución y orden público laboral. Un análisis del art. $19 N^{\circ} 16$ de la Constitución chilena. Segunda edición. Ediciones Universidad Alberto Hurtado, Santiago, 2012.

JUNGER, Ernest: El trabajador. Dominio y figura. Tercera edición. Editorial Ensayo Tusquets, Barcelona, 2003.

LIZAMA, Luis y UGARTE, José Luis: Interpretación y derechos fundamentales en la empresa. Editorial Jurídica Cono Sur Ltda., Santiago, 1998.

LIZAMA, Luis: Derecho del Trabajo. Editorial Lexis Nexis, Santiago, 2003.

MEDA, Dominique: "El valor del Trabajo visto en perspectiva". En: Revista Internacional del Trabajo, vol. 115, Nº6, 1996. pp. 689-700. 
MELIS, Christian: Los derechos fundamentales de los trabajadores como límites a los poderes empresariales. Legal Publishing, Santiago, 2009.

NASH, Claudio y MEDINA, Cecilia: "Manual de derecho internacional de los derechos humanos". 2003. Disponible en: ttps://www. fundacionhenrydunant.org/images/stories/biblioteca/derechos_humanos/ MEDINA_C._y_NASH_C._2003.Manual_de_Derecho_Internacional_ de_los_DDHH.pdf. Fecha de consulta: 13 de marzo de 2018.

OSTAU DE LAFON, Francisco: El Derecho Internacional Laboral. Editorial Universidad Católica de Colombia, Bogotá, 2015.

PALAVECINO, Claudio: "La libertad de trabajo y su protección constitucional. Nueva lectura”, Revista laboral chilena, vol. 8, № 219, 2013. p.p 79-83.

ROJAS, Irene: Derecho del Trabajo. Derecho individual del Trabajo. Editorial Thomson Reuters, Santiago, 2015.

SUPIOT, Alain: Derecho del Trabajo., Editorial Eliasta, Buenos Aires, 2008.

THAYER, William y NOVOA, Patricio: Manual del Derecho del Trabajo. Tomo IV. Octava Edición. Editorial Jurídica de Chile, Santiago, 2015.

UGARTE, José Luis: El nuevo derecho del Trabajo. Tercera edición. Editorial Legal Publishing, Santiago, 2011.

UGARTE, José Luis: Derechos Fundamentales en el Contrato de Trabajo. Editorial Thomson Reuters, Santiago, 2013.

QUINZIO, Jorge Mario: Tratado de derecho Constitucional. Tomo I. Editorial Lexis Nexis, Santiago, 2006.

WALKER, Francisco: Nociones Elementales de Derecho del Trabajo. Editorial Nascimiento, Santiago, 1941.

ZIZEK, Slavoj: Repetir Lenin. Editorial Akal, Madrid, 2004.

\section{Normas Citadas}

-Constitución Politica de la república de Chile, Editorial Lexis Nexis, Santiago, 2006;

-Código del Trabajo, Edición oficial, Editorial Jurídica de Chile, Santiago, 2013;

-Decreto Ley 778, que promulga el Pacto Internacional de derechos económicos, sociales y culturales Fecha de publicación: 29 de abril de 1989. 
